\title{
Analysis of Parental Views on the Value of Children
}

\author{
Anisatul Khoiroh ${ }^{1, *}$, Yeni Rachmawati ${ }^{2}$, Vina Adriany ${ }^{3}$ \\ ${ }^{1,2,3}$ Department Early Childhood, School of Postgraduate. Universitas Pendidikan Indonesia \\ *Corresponding author email: anisatulkhioroh374@upi.edu
}

\begin{abstract}
Previous research on the value of children often focuses on the economic values of children. This research adopts literature approaches which discuss children's value from a parent's perspectives. This paper adopts literature reviews to see how, children's values are influenced by other factors. The finding suggests that culture and social factors contribute significantly to the construction of children's value. Findings of this research indicate the direction of future research in the field to explore social-cultural factors that shape the value of children.
\end{abstract}

Keywords: Value of children, parents, cultural.

\section{INTRODUCTION}

The concept of children's values is undoubtedly closely related to how the family views children and their parenting style. Minuchin pointed out that family refers to a system consisting of father, mother, and child with different roles [1]. Both parents and children have a relationship that plays an essential role in a family's resilience as it affects the parents' perceptions towards their children. The parents' perceptions of their children's reasons and expectations are commonly referred to as the children's values [2].

The concept of children's values becomes part of cultural values or beliefs in a society. The children's values are defined as a view or assessment towards the meaning and function of having children in the family. In general, children have considered what parents need, regarding the economic, social, or psychological needs. There are positive and negative sides to the children's value, which are considered the overall values [2], [3]. The positive value was the parents' satisfaction or usefulness, while the negative one is the cost or burden brought by the existence of children.

The children's values are related to how parents perceive the presence of children. These values are significant as the attitudes of parents will get affected. There are three dimensions of children's values: the psychological-emotional value of children, the economic-utilitarian value of children, and the socialnormative value of children [4]. The children's values in the psychological dimension are related to the parents' perception towards their children as something that provides happiness and economic value; it is related to parents who have children to invest in the family. Meanwhile, the social values are the parents' values in assuming the children as the good bearers.

Parents get a different point of view on the children's values. Every parent has his objective soon after the decision of having children being realized. The researchers wanted to find out more about the children's values in various countries by collecting the existing research.

\section{METHOD}

The researchers used the literature review method to get a deep understanding of which was done with the other ones [5]. This article discussed the concept of children's values by exploring the parents' perceptions of children's values from their point of view through previous researches.

\section{THE PARENTS' PERCEPTION ON THE CHILDREN'S VALUES}

Perception is defined as how an individual views or believes what he experiences. Perception is a process of interpreting sensory impressions as an effort to provide a particular meaning to the environment based on the philosophy of truth or direct belief in something [6]. Thus, parents' perceptions are the process of interpreting their sensory impressions as an effort to provide a particular meaning to everything they avoid based on their hunch on the truth or beliefs.

Children's values play as the functions or expectations done or fulfilled by their parents' needs [7]. 
These values become parts of the cultural values in a society. The children's value becomes the assessment of a person or society towards what they function and are meant to parents. Children are generally considered one of the parents' needs concerning economic, social, and psychological. According to Chrome [8], the children's values to their parents in everyday daily life is based on the fact that children become places for parents to devote their affections and complaints, sources of happiness, being a consideration when parents want to divorce, socialization forum and preserving the values in the family and in which the family assets are inherited, and parents' assets in the future.

The focus of this research was on the children's values in parents' perceptions. This research focusing on the children's values was easy to find in various parts of the world. Focusing on children's values, the researcher tried to get more in-depth information about the concept of children's values in terms of several dimensions of the values themselves by reviewing several articles related to children's values. Currently, much attention is being given to the children's values and their development in an educational context. The values and expectations from the research entitled "Assessing Children's Values: An Exploratory Study" showed that parents had high demands on children's language skills, cognitive skills, and the ability to think abstractly [9]. Parents' demands on children did not appear automatically but were based on their views. Comparisons across generations, cultures, and socioeconomic levels made differences in parents' goals and expectations on children's values [10]. Parents' social class and work experience also influenced the value of raising their children [11]. The results of his research indicated that work experience mediated the relationship between father's social class and view values about children's values. Ataca [12] constructed children's values using several theories of family change from various perspectives. The results showed that the values associated with children determined the role of offspring as providers for parents, and elderly care became the norm. Other studies have shown the result of an investigation on how parents chose the value of socialization could shed light on our understanding of the shared values of parents and children [13]. This research discussed the implications of these findings for the theoretical understanding of the socialization of children's values and functions.

The research entitled "Values of Children, ParentChild Relationship, and Social Change in Korea: Indigenous, Cultural, and Psychological Analysis" examined the reasons why parents decided whether or not to have children and the number of children they chose to have [14]. The results showed that psychological benefits were the fundamental reasons for having children, while personal and financial constraints were essential for not having children. Dyer [15] explained the motivation of parents to have children. In his research, he argued that children were mostly wanted for reasons related to happiness and well-being. Meanwhile, research conducted by Cieciuch [16] and colleagues explained parents' description of children's values by measuring four values that were self-transcendence, selfimprovement, openness to change, and conservation.

Research conducted by Hoffman \& Manis [2], [3] described the response to the benefits of having children obtained from interviews with black, white, and Hispanic couples. The results showed that responses indicated that children had something useful to do, made parents feel like better people, and had an economic utility positively related to family size. Simultaneously, some responded that children were seen as functional for marriage in a negative way. It was related to which parents attributed these values to their children and what benefits were expected from the children assessed in the context of socioeconomic development. In particular, in the Kagitçibasi study [17], it was found that with this development, the guarantee value of the child's old age decreased, which appeared to be the primary process contributing to lower fertility as well as for modifying values regarding children's care and place [17]. Thus, children's value formed a clear link at the individual level between development and decline in infertility.

Konrad [18] recommended parenting by parents as the value of seeking guidance and appreciating the little things in life. Simultaneously, practical advice included encouraging parents to gain information and advocating for their children's best interests. Mothers also identified the professionals with end-of-life training as important support agents. Klaus et al. [19] argued that children's specific values proved to have only minimal predictive power concerning the birth of children of different parties, which was against expectations. Nauck, B. [4] explained that traditional economic theory emphasized the cost of children. The children's value approach included the children's reserve side, namely the benefits children provided to their (potential) parents under various social and economic conditions. In their research, Tam and Lee [20] described the values that parents like to their children. It highlighted the need to consider the concept of norms in understanding family socialization. The implications for cultural psychology research were also discussed. Chiang [21] exposed the model of motivation and expectation applied to understand children's choices in the academic sports field. The result of the research showed that the perceived cost empirically different from the competency belief and other kinds of values that mentioned perceived cost marginally related to the level of physical activity reported by the children, and children's beliefs and values related to the level of physical activity reported by them. The children's perceived cost was varied depending on the level and gender. 
Nauck and Klaus [22] showed the importance of having children for convenience was the top reason for a country with high fertility rates with lineage-based kinship systems and shared prosperity. Countries with low fertility and high affluence levels also assumed that having children was a convenience but low variation than in countries with high fertility rates. According to Piccinini's research [23], parents tended to respect autonomy and self-direction when children were 36 months old rather than 3 or 72 months old. Middleclass parents tended to respect their children at the age of 36 years old or older than when they were younger or older.

Research by Tulviste and Ahtonen [24] explained that the value of raising children was not different by gender, but it depends on the cultural context. Finnish parents tended to highlight virtue, hedonism, and bad habit rather than suitability and achievement; the value of raising children was more homogeneous, and the values held by mother and father from the same family revealed more similarities. Estonian mothers are more concerned with virtue and obedience rather than Estonian fathers. Research results by Barni [25] explained more about the Italian homogeneous value context. The value similarity of parents and children increased by a broad social-cultural context. It was better seen as a common similarity with a national standard. Otherwise, in a less homogeneous context from Israel, when counting on the effect of the normative profile, there was still a unique similarity with the subjects that were mother and children from the Arabian group.

\section{CONCLUSION}

Based on the research result, it can be concluded that the children's value in the family can be seen from several perspectives. The children's values were different from one culture and country. Therefore, it is essential to show that there was no hegemonic value, and thus another value was negated. It is not only about the economic factor that affected the children's values, but also social and cultural factors. Psychological factors also affected the parents' expectations and desire to have children. Parents who have children with psychological basis believed that children were a gift to share affection. Parents who have children value social basis believed that by having children, they have a successor for the family generation and expected that the children could maintain the family dignity. Whereas, the family who has children valued with economic basis believed that by having children, they have a future asset that will take care of them in old age.

\section{ACKNOWLEDGMENTS}

This paper has been supported by many parties. The researcher would like to express his gratitude for the Research institute and community service, Indonesian education university, Indonesian Ministry of Research and Education.

\section{REFERENCES}

[1] Goldenberg. Family therapy an overview. Belmont: Brooks/Cole. 2000

[2] Hoffman L, Manis J. The value of children in the United States: A new approach to the study of fertility. Journal of Marriage and Family. 1979; 41(3):583-96. DOI:10.2307/351628.

[3] Hoffman L, Thornton A., \& Manis J. The value of children to parents in the United States. Journal of Population [Internet]. 1978;1(2):91-31. Available from: http://www.jstor.org/stable/27507564.

[4] Nauck B. Value of children and the social production of welfare. Demographic Research. 2014;30(1):1793-824. Available from: https://doi.org/10.4054/DemRes.2014.30.66.

[5] Gay LR, Geoffrey EM, Peter A. Educational research: Competencies for analysis and applications. Tenth Edition. Upper Saddle River: Pearson Education, Inc. 2012.

[6] Siagian, Sondang P. Teori motivasi dan aplikasinya. Jakarta: Bina Aksara. 2004.

[7] Espenshade TJ. The value and cost of children. Population bulletin. 1977 Apr;32(1):1-80.

[8] Ihromi. Bunga rampai sosiologi keluarga. Jakarta: Obor. 1999.

[9] Döring AK. Assessing children's values: an exploratory study. Journal of Psychoeducational Assessment. 2010;28(6):564-77. Available from: https://doi.org/10.1177/0734282909357151.

[10] Aycicegi-dinn A. The value of children for parents in the minds of emerging adults. Cross-Cultural Research. 2010;44(2):174-05. Available from: https://doi.org/10.1177/1069397109358389.

[11]Brazil S, Dal G, Martins F, Gonçalves T R, Marin AH, Piccinini CA, et al. Social class, workplace experience, and child rearing values of mothers and fathers in Shoutern Brazil. Journal of Cross-Cultural Psychology. 2015;46(8):996-009. Available from: https://doi.org/10.1177/0022022115597067.

[12] Ataca B. Value of children, family change, and implications for the care of the elderly. CrossCultural Research. 2015;49(4):374-92. Available from: https://doi.org/10.1177/1069397115598139.

[13] Chan H, Tam K. Understanding the lack of parentchild value similarity: The role of perceived norms in value socialization in immigrant families. Journal of Cross-Cultural Psychology. 2016;47(5):651-69. Available from: https://doi.org/10.1177/002202211 6635744 . 
[14] Child P, Kim U, Park Y, Koo J. Values of children, parent-child relationship, and social change in Korea: indigenous, cultural, and psychological analysis. International Association for Applied Psychology. 2005;54(3):338-54.

[15]Dyer SJ. The value of children in African countriesinsights from studies on infertility. Journal of Psychosomatic Obstetrics and Gynaecology. 2007;28(2):69-77. Available from: https://doi.org/10.1080/01674820701409959.

[16]Cieciuch J, Harasymczuk J, Döring AK. Structural Validity of the polish adaptation of the picture-based value survey for children (PBVS-C). Journal of Psychoeducational Assessment. 2013;31(4):404-09. Available from: https://doi.org/10.1177/073428291 2453125.

[17] Kagitçibasi Ç. Old-age security value of children: cross-national socioeconomic evidence. Journal of Cross-Cultural Psychology. 1982;13(1):29-42. Available from: https://doi.org/10.1177/00220221 82131004

[18] Konrad SC. What parents of seriously ill children value: Parent-to-parent connection and mentorship. Omega: Journal of Death and Dying [Internet]. 2007;55(2):117-30. Available from: https://doi.org/10.2190/OM.55.2.b.

[19] Klaus D, Suckow J, Nauck, B. The value of Children in Palestine and Turkey. International Sociological Association. 2007;527-44. Available from: https://doi.org/10.1177/0011392107077637.

[20]Tam K, Lee S. What values do parents want to socialize in their children? the role of perceived normative values. Journal of Cross-Cultural Psychology. 2010;41(2):175-81. Available from: https://doi.org/10.1177/0022022109354379.

[21] Chiang ES, Byrd SP, Molin AJ. Children's perceived cost for exercise: application of an expectancy-value paradigm. Health Education \& Behavior. 2011;38(2):143-49. Available from: Available from: https://doi.org/10.1177/1090198110376350.

[22] Nauck B, Klaus D. The varying value of children. International Sociological Association. 2007:48703. Available from: https://doi.org/10.1177/001139210707734.

[23] Piccinini CA, Sperb TM, Chipenda DS, Marin AH, Vivian AG, Oliveira DS. et al. Child-rearing values in Southern Brazil: mutual influences of social class and parents' perceptions of their children's development. Journal of Family Issues. 2012;34(10):1379-400. Available from: https://doi.org/10.1177/0192513X12453820.

[24] Tulviste T, Ahtonen M. Child rearing values of Estonian and Finnish mothers and fathers [Internet]. Journal of Cross-Cultural Psychology.
2007;38(6511):137-55. Available from: https://doi.org/10.1177/0022022106297297.

[25]Barni D, Knafo A, Ben-arieh A, Haj-yahia MM. Parent-child value similarity across and within cultures. Journal of Cross-Cultural Psychology. 2014;45(6):853-67. Available from: https://doi.org/10.11770022022114530494. 